\title{
Medical and nutritional implications in chronic heart failure: Strengths and limitations
}

\author{
Implicaciones médicas y nutricionales en insuficiencia cardiaca crónica: fortalezas y \\ limitaciones
}

Lucero Rico-de la Rosa ${ }^{1}$, Miguel Robledo-Valdez ${ }^{1}$, Enrique Cervantes-Pérez ${ }^{1,2 *}$, Gabino Cervantes-Guevara ${ }^{2,3}$, Guillermo A. Cervantes-Cardona ${ }^{4}$, Sol Ramírez-Ochoa ${ }^{5}$, Alejandro González-Ojeda ${ }^{6}$, Clotilde Fuentes-Orozco ${ }^{6}$, and Ma. Fernanda Padilla-Rubio ${ }^{1}$

${ }^{1}$ Department of Clinical Nutrition, Instituto Nacional de Ciencias Médicas y Nutrición "Salvador Zubirán", Mexico City; ${ }^{2}$ Department of Welfare and Sustainable Development, University Center of the North, Universidad de Guadalajara, Colotlán, Jal.; ${ }^{3}$ Gastroenterology Department, Hospital Civil de Guadalajara "Fray Antonio Alcalde", Guadalajara, Jal.; " ${ }^{4}$ epartment of Philosophical, Methodological and Instrumental Disciplines, University Center of Health Sciences, Universidad de Guadalajara, Guadalajara, Jal.; ${ }^{5}$ Department of Internal Medicine, Hospital Civil de Guadalajara "Fray Antonio Alcalde", Guadalajara, Jal.; 'Biomedical Research Unit 02, UMAE, Specialty Hospital, National Medical Center of the West, IMSS, Guadalajara, Jal., Mexico

\begin{abstract}
Heart failure (HF) is one of the most important global public health problems, as there is an increase in its prevalence and an estimated 23 million of the world's population live with this problem. HF is defined by the presence of structural and functional abnormalities of the cardiac muscle leading to an impairment of ventricular filling and ejection. Multiple comorbidities have been associated with an increased risk of developing cardiovascular diseases. Hypertension has been recognized as one of the most important factors, however, obesity, metabolic syndrome, as well as diabetes also play an important role in the onset of the disease. It is common to find in decompensated heart failure hospitalized patients an impaired nutritional status characterized mainly by the presence of nutritional deficiencies and sarcopenia, which can sometimes progress to cachexia. Therefore, an adequate evaluation through the correct use of nutritional risk tools should be the cornerstone to the prevention of risks. Multiple anthropometric and biochemical parameters are available to establish the nutritional status of hospitalized patients, however, alterations in blood volume presented in patients with HF may alter the result of such assessment. The effectiveness of dietary modifications in the prevention and treatment of different cardiovascular diseases enhanced by appropriate adherence to eating patterns such as the DASH and Mediterranean diet have been inversely associated with the incidence of HF.
\end{abstract}

Key words: Malnutrition. Insulin resistance. Nutritional risk. Heart failure. Cardiac cachexia.

\section{Resumen}

La insuficiencia cardiaca (IC) representa uno de los problemas mundiales de salud pública más importantes, ya que existe un aumento en su prevalencia y se estima que 23 millones de la población mundial viven con este problema. Esta entidad

\section{Correspondence:}

*Enrique Cervantes-Pérez

E-mail: enrique.cervantes@academico.udg.mx

DOI: 10.24875/ACME.M21000200
Date of reception: 04-06-2020

Date of acceptance: 07-03-2021 license (http://creativecommons.org/licenses/by-nc-nd/4.0/).

Available online: 19-07-2021

Arch Cardiol Mex (Eng). 2021;91(2):189-196

www.archivoscardiologia.com 
se define por la presencia de anormalidades estructurales y funcionales del músculo cardiaco que conducen a un deterioro en la capacidad del llenado y eyección ventricular. Múltiples comorbilidades se han asociado a un incremento en el riesgo de desarrollo de enfermedades cardiovasculares. La hipertensión se ha reconocido como uno de los factores más importantes, sin embargo, la obesidad, el síndrome metabólico, así como la diabetes, también juegan un papel importante en la aparición de dicha enfermedad. Es frecuente encontrar en pacientes hospitalizados con IC deterioro en el estado nutricional caracterizado principalmente por la presencia de deficiencias nutricionales y sarcopenia, que, en ocasiones, puede progresar y manifestarse como caquexia. Por lo anterior, una evaluación adecuada mediante el uso correcto de herramientas para detección de riesgo nutricional es imperativa, se hace necesaria para prevenir los riesgos que esto implica. Existen múltiples parámetros antropométricos y bioquímicos para definir el estado nutricional de los pacientes hospitalizados, sin embargo, las alteraciones en el volumen sanguíneo presentes en pacientes con IC pueden alterar el resultado de dicha evaluación. Las modificaciones dietéticas en la prevención y tratamiento de diversas enfermedades cardiovasculares mediante un buen apego a patrones de alimentación tales como la dieta DASH (enfoques dietéticos para detener la hipertensión, por sus siglas en inglés) y la dieta mediterránea se han asociado inversamente con la incidencia de IC.

Palabras clave: Desnutrición. Resistencia a la insulina. Riesgo nutricional. Insuficiencia cardiaca. Caquexia cardiaca.

\section{Introduction}

Heart failure (HF) is a complex clinical disorder characterized by dyspnea, fatigue and fluid retention, accompanied by relevant clinical signs (pulmonary crackles, elevated jugular venous pressure and peripheral edema). In addition to functional impact, HF is clearly associated with a higher probability of hospitalization, as well as with high mortality ${ }^{1}$. It affects 6.2 million US adults, with an incidence close to 21 per 1,000 population after 65 years of $a^{2} e^{2}$, and with total cost of care exceeding 30 billion dollars annually. Projections estimate that, by 2030, more than 8 million people older than 18 years will be affected by the disease and that the cost of care by then will be higher than 70 billion dollars due to population aging and growth ${ }^{3}$.

A 2015 disease cost analysis that assessed the economic impact of four heart conditions in Mexico conservatively estimated that these diseases had a financial cost of 96.4 billion pesos ( 6.1 billion dollars). Myocardial infarction imposed the highest cost (39 billion pesos $/ 2.5$ billion dollars), followed by HF (27 billion/1.7 billion), hypertension (22.7 billion/1.5 billion) and, finally, atrial fibrillation (8.4 billion/532 million). The burden of these four conditions accounted for approximately $4 \%$ of total national health expenditure ${ }^{4}$.

The association between the presence of chronic diseases and nutritional status deterioration has long been recognized, as well as the negative impact this generates on people's quality of life and, consequently, an increase in the risk of morbidity and mortality ${ }^{5}$.

Nutritional status and HF have strong associations. Deficiencies in the levels of micronutrients, such as thiamine and selenium, for example, are well described as a cause of cardiomyopathy. However, malnutrition is more common in patients with chronic HF, sometimes progressing to overt cardiac cachexia (CC), which is characterized by caloric-protein malnutrition with muscle wasting and peripheral edema ${ }^{6}$. Chronic HF is a condition characterized by systemic venous congestion. Malnutrition in chronic HF could be related to right-sided heart failure and congestion, which predispose to intestinal edema, inflammatory activation and malabsorption, thus leading to malnutrition and cachexia ${ }^{7}$.

\section{Heart failure and impaired nutritional status: pathophysiological links}

Chronic HF, impaired nutritional status and muscle wasting share many common pathophysiological processes. The causes that contribute to wasting in HF are multifactorial. Intestinal hypoperfusion and interstitial edema cause nausea and anorexia, as well as nutrient malabsorption. Neurohormonal activation with increased activity of the sympathetic nervous system and renin-angiotensin-aldosterone system lead to an increase in basal energy expenditure and, therefore, induce a catabolic state ${ }^{8}$.

An additional imbalance between anabolic and catabolic metabolism in these patients is triggered by a reduction of anabolic mediators, including growth hormone, insulin-like growth factor 1 , testosterone and ghrelin, as well as an increase in inflammatory mediators, such as tumor necrosis factor-alpha (TNF- $\alpha$ ), interleukin-6 (IL-6) and C-reactive protein (CRP), with a consequent increase in oxidative stress ${ }^{9}$.

Patients with HF are also more vulnerable to nutritional deficiencies due to the presence of multiple comorbidities such as hypertension, coronary artery disease, diabetes mellitus, atrial fibrillation, chronic lung 
disease, chronic kidney disease, chronic liver disease and anemia ${ }^{10}$. Patients with HF may also experience nutritional status worsening and wasting when evolving to a fraility phenotype, which constitutes a multidimensional syndrome, characterized by a loss of lean body mass (sarcopenia), weakness and decreased resistance to physical exercise, which leads to decreased activity and poor response to stress. Reduced activity, in turn, worsens sarcopenia and weakness, which leads to a spiraling trend towards functional impairment and increases the risk of death ${ }^{11}$. Since there is no strict definition of how fraility in HF should be assessed, there is significant variability in prevalence, from $21 \%$ in outpatient adults to $70 \%$ in hospitalized patients with acute decompensated $\mathrm{HF}^{8,12,13}$.

\section{Sarcopenia in patients with heart failure}

The term sarcopenia indicates an age-related loss of the amount or quality of skeletal muscle and a decrease in muscle strength and/or physical performance not necessarily associated with weight loss ${ }^{14}$. Von Haehling describes the "continuous wasting in HF". He suggests that, given that sarcopenia predominantly affects postural rather than non-postural muscles, and cachexia leads to fatty tissue loss, as well as weight loss, continuous wasting in HF implies that skeletal muscle is lost prior to adipose tissue and, therefore, sarcopenia precedes cachexia ${ }^{15}$. Its prevalence is higher than $20 \%$ when healthy subjects of the same age are compared. Sarcopenia is characterized by abnormalities in energy metabolism, along with mitochondrial dysfunction and myofiber atrophy, with transition from type I to type $\mathrm{I}^{16}$, and a progressive denervation and re-innervation process, probably secondary to a chronic neuropathic process that results in the loss of the motor unit. Said change is responsible for lower oxidative capacity and slower contraction speed, which causes exercise intolerance and, in turn, a decrease in skeletal muscle mass ${ }^{17}$. Another factor that contributes to sarcopenia in the patient with $\mathrm{HF}$ is the participation of inflammatory cytokines, which can induce anorexia ${ }^{16}$.

\section{Cardiac cachexia}

Chronic HF-associated cachexia is known as cardiac cachexia (CC), the prevalence of which ranges between 5 to $15 \%$. It is defined as the loss of at least $5 \%$ of edema-free body weight within previous 12 months (or a body mass index [BMl] $<20 \mathrm{~kg} / \mathrm{m}^{2}$ ) in patients with chronic disease and at least three of the following clinical or laboratory criteria: muscle strength decrease, fatigue, anorexia, low fat-free mass index and abnormal biochemistry characterized by increased inflammatory markers (CRP, IL-6), anemia (hemoglobin $<12 \mathrm{~g} / \mathrm{dL}$ ) and/ or low serum albumin $(<3.2 \mathrm{~g} / \mathrm{dL})^{18}$. CC is related to hemodynamic alterations such as congestion, with consequent pro-inflammation, malabsorption, anorexia, and neurohormonal activation. The presence of $C C$ is a predictor of poor prognosis, including all-cause death ${ }^{19}$.

\section{Nutritional deficiencies in patients with heart failure}

One of the biggest risks in patients with HF is decreased caloric intake, given that it is associated with a lower quality of life and nutritional deficiencies that might lead to cardiovascular events ${ }^{20}$. Chronic deficiencies of various micronutrients can favor the development of HF, among which some are: coenzyme Q10 (CoQ10), thiamine (B1), L-carnitine, taurine and selenium. These five micronutrients are essential components for the metabolic pathways involved in energy production, myocardial calcium balance and/or oxidative defenses (levels are significantly reduced in patients with $\mathrm{HF})^{21}$.

\section{Coenzyme Q10}

The most prominent role of CoQ10 is to facilitate the production of adenosine triphosphate (ATP), thus participating in redox reactions within the electron transport chain, where CoQ10 accepts electrons from complexes I and II and transports them to complex III22. This coenzyme can potentially improve heart function through a variety of mechanisms, since it appears to be a powerful antioxidant that improves endothelial dysfunction and possibly cardiac ATP production. Therefore, when CoQ10 levels are low, they are associated with HF symptoms higher severity ${ }^{22}$.

Sander et al. describe that CoQ10 improves sistolic function in patients with HF, with a statistically significant change being observed when compared to placebo $^{23}$. It also appears to be a safe and effective nutritional supplement for the treatment of HF, with a reduction in morbidity and mortality being observed in those patients who already receive standard therapy ${ }^{24}$.

\section{Thiamine (B1)}

Thiamine (B1) is a water-soluble vitamin, which plays an important role as a coenzyme in carbohydrate 
metabolism. By magnesium and ATP addition, thiamine is converted into thiamine pyrophosphate by the action of thiamine pyrophosphokinase ${ }^{24}$. Deficiency of this vitamin can occur in patients with HF due to a combination of factors, including malnutrition and increased urinary losses caused by diuretic-based therapy (frequently with furosemide) ${ }^{25}$.

Schoenenberger et al. conducted a randomized, double-blind, crossover, placebo-controlled study, which included nine patients with left ventricular ejection fraction (LVEF) $<40 \%$. After 28 days of oral treatment with $300 \mathrm{mg}$ of thiamine, LVEF increased to $32.8 \%$, which was significantly different $(p=0.024)$ from LVEF in the placebo group (28.8\%). This study showed that B1 supplementation has beneficial effects on cardiac function in patients with chronic symptomatic $\mathrm{HF}^{26}$.

\section{L-carnitine}

L-carnitine is a derivative of amino acids, synthesized mainly from lysine and methionine ${ }^{27}$. Studies suggest that L-carnitine plays a role in the use of fatty acids and glucose in the myocardium ${ }^{28}$. One of the manifestations caused by carnitine primary deficiency in children is dilated cardiomyopathy; however, it is not yet clear whether this type of cardiomyopathy can be observed in adults 29 .

To assess the prognostic impact of carnitine supplementation on HF, Rizos conducted a double-blind, controlled trial of $2 \mathrm{~g} /$ day of L-carnitine vs. placebo, and found a decrease in the mortality rate for L-carnitine-treated patients that was statistically significant at three years $(18 \%$ in the placebo group vs. $3 \%$ in the L-carnitine group, $\mathrm{p}<0.04$ ) in patients with $\mathrm{HF}^{30}$.

\section{Taurine}

Taurine deficiency at the cardiac level generates deterioration in aerobic metabolism and has been associated with a reduction in oxygen consumption, an increase in glycolysis and increased lactate concentration, as well as decreased ATP activity ${ }^{20}$. Taurine supplementation might provide an antioxidant benefit, since this amino acid is a scavenger for the hypochlorite anion and forms taurochloramine ( $\mathrm{TauCl})$. $\mathrm{TauCl}$ is a powerful antioxidant and anti-inflammatory agent, since it inhibits the generation of prostaglandins, TNF- $\alpha$ and IL-6. Evidence identifies taurine as a cardioprotective agent, since it can reduce atherogenesis and, owing to this, it plays a prominent role in maintaining cardiomyocytes normal physiology ${ }^{31}$.

\section{Selenium}

Selenium is an essential micronutrient for the human body, given that it is necessary for the synthesis of selenoproteins, which have important pleiotropic biological activities, including antioxidant activity, anti-inflammatory activity and deiodinase activity (which is necessary for the synthesis of active thyroid hormone). Selenium deficiency manifests itself in different ways, such as epilepsy and cardiovascular injury that in some cases evolves into $\mathrm{HF}^{32}$. Keshan disease is the classic clinical presentation of heart disease secondary to selenium deficiency, which often exhibits clinical characteristics of dilated cardiomyopathy: cardiogenic shock, arrhythmias, electrocardiogram abnormalities, cardiomegaly and/or $\mathrm{HF}^{33}$.

Primary treatment of selenium deficiency cardiomyopathy is supplementation of said micronutrient and parenteral nutrition. Patients with confirmed evidence of HF could receive carvedilol, a non-selective beta-blocker that suppresses reactive oxygen species with antioxidant and anti-inflammatory effect ${ }^{21}$.

\section{Nutritional assessment in patients with heart failure}

Several tools have been proposed to assess malnutrition in patients with chronic HF and, in general, they can be classified as simple or multidimensional tools ${ }^{34}$. Simple tools analyze malnutrition by considering laboratory tests and anthropometric measurements (Table 1); on the other hand, multidimensional tools provide a more comprehensive assessment of nutritional status by evaluating a variety of factors, including acute diseases, mobility, comorbidities and dietary intake.

A recent study where the nutritional status of $467 \mathrm{pa}-$ tients with chronic HF was evaluated, showed that the variation in the prevalence of malnutrition (of any grade and at least moderate) is much higher when simple tools are used (any grade: 6-60\%; at least moderate: 6-9\%) in comparison with multidimensional tools (any grade: $12-29 \%$; at least moderate: $3-4 \%$ ). The nutritional control (CONUT) index score, which uses serum albumin, total cholesterol, and plasma lymphocyte count, suggested that many more patients were "undernourished" in comparison with the geriatric nutritional risk index (GNRI), which uses serum albumin and weight, or the prognostic nutritional index (PNI), which combines serum albumin with total lymphocyte count. There was a higher degree of agreement in the 
Table 1. Biochemical parameters for malnutrition diagnosis

\begin{tabular}{|l|l|}
\hline Albumin & $\begin{array}{l}\text { Half-life of } 20 \text { days } \\
\text { Low levels of undernourishment. Also in } \\
\text { infections, burns, fluid overload, liver } \\
\text { failure, cancer and nephrotic syndrome }\end{array}$ \\
\hline Transferrin & $\begin{array}{l}\text { Half-life of } 10 \text { days } \\
\text { Low levels in caloric-protein } \\
\text { undernourishment, sensitive to serum iron } \\
\text { change }\end{array}$ \\
\hline Pre-albumin & $\begin{array}{l}\text { Half-life of 2-3 days } \\
\text { Low levels in undernourishment. Also in } \\
\text { infections and liver failure, and there is } \\
\text { an increase in kidney damage }\end{array}$ \\
\hline C-reactive protein & $\begin{array}{l}\text { Positive acute-phase reactant. Helps to } \\
\text { determine if previous proteins are } \\
\text { reduced due to inflammatory processes } \\
\text { or to an inadequate substrate, as in } \\
\text { undernourishment }\end{array}$ \\
\hline
\end{tabular}

identification of undernourished patients using multidimensional tools in comparison with simple tools ${ }^{7}$.

Different tools have their own strengths and weaknesses. Among simple detection tools, the CONUT score has the highest sensitivity, but also has the highest rate of false positives for identifying at least moderate malnutrition. PNI, although specific, has the highest rate of false negatives in the identification of undernourishment of any grade, with undernourishment thus being underestimated in comparison with other instruments. This is because PNI lacks a mild undernourishment category and only identifies patients with at least moderate undernourishment. GNRI appears to be the best simple screening tool for malnutrition in patients with chronic $\mathrm{HF}$, but only when $\mathrm{BMI}$ is $<30^{7}$.

Multidimensional tools provide a more comprehensive assessment of nutritional status and have stricter criteria for identifying malnutrition in comparison with simple tools; although they classify a smaller proportion of subjects as undernourished, they are probably more accurate for undernourishment detection. The Malnutrition Universal Screening Tool (MUST) score and the mini-nutritional assessment (MNA) are commonly used in different settings: hospitals, clinics, general practice and nursing homes ${ }^{35}$.

MNA-SF, a MNA shorter version, is faster to be completed and has similar validity and accuracy to those of MNA for the detection of undernourishment in older adults $^{36}$.

Subjective Global Assessment (SGA) is the most comprehensive among the three multidimensional tools. It considers weight change, dietary changes, gastrointestinal symptoms and functional capacity. In addition, a significant proportion of the evaluation depends on the results of a full physical examination. Like MNA-SF, SGA also has a low misclassification rate in the detection of significant undernourishment. However, SGA is subjective and not sensitive for detecting malnutrition in obese patients. It also requires significant time to be carried out (a mean of 20 minutes) ${ }^{7}$.

\section{Nutritional intervention in patients with heart failure}

Observational studies have demonstrated that patients with HF usually have insufficient energy and protein intake, and it has been suggested that nutritional interventions aimed at increasing their intake could lead to a better adjustment mechanism in anabolic/catabolic imbalances caused by the process of inflammation and neurohormonal activation, which are common among patients with $\mathrm{HF}^{37}$.

Nutritional intervention in these patients should first consider the BMI (edema-free) of any individual, so that it can be stratified as low, normal and high in order to estimate the amount of caloric intake, as well as dietary macronutrients composition ${ }^{38}$. Figure 1 summarizes nutritional indications in patients with $\mathrm{HF}$, according to edema-free BMI.

\section{Dietary recommendations in patients with heart failure}

The effectiveness of dietary modifications in the prevention and treatment of various types of cardiovascular diseases is well recognized. The dietary approaches to stop hypertension (DASH) diet, as well as the Mediterranean diet, have been inversely associated with the incidence of $\mathrm{HF}^{39,40}$.

Both nutrition patterns share their main components, except that the DASH diet does not specifically promote the consumption of monounsaturated, polyunsaturated and omega-3 fatty acids, and restricts sodium consumption ${ }^{40}$.

Multicenter cohort studies evaluated the effect of the Mediterranean diet and found a significant reduction in $\mathrm{HF}$ evolution, as well as an increase in ventricular function preservation, due to improvements in systolic and diastolic pressure, as well as in endothelial function. On the other hand, one study showed that appropriate adherence to the DASH diet had a positive effect on left 


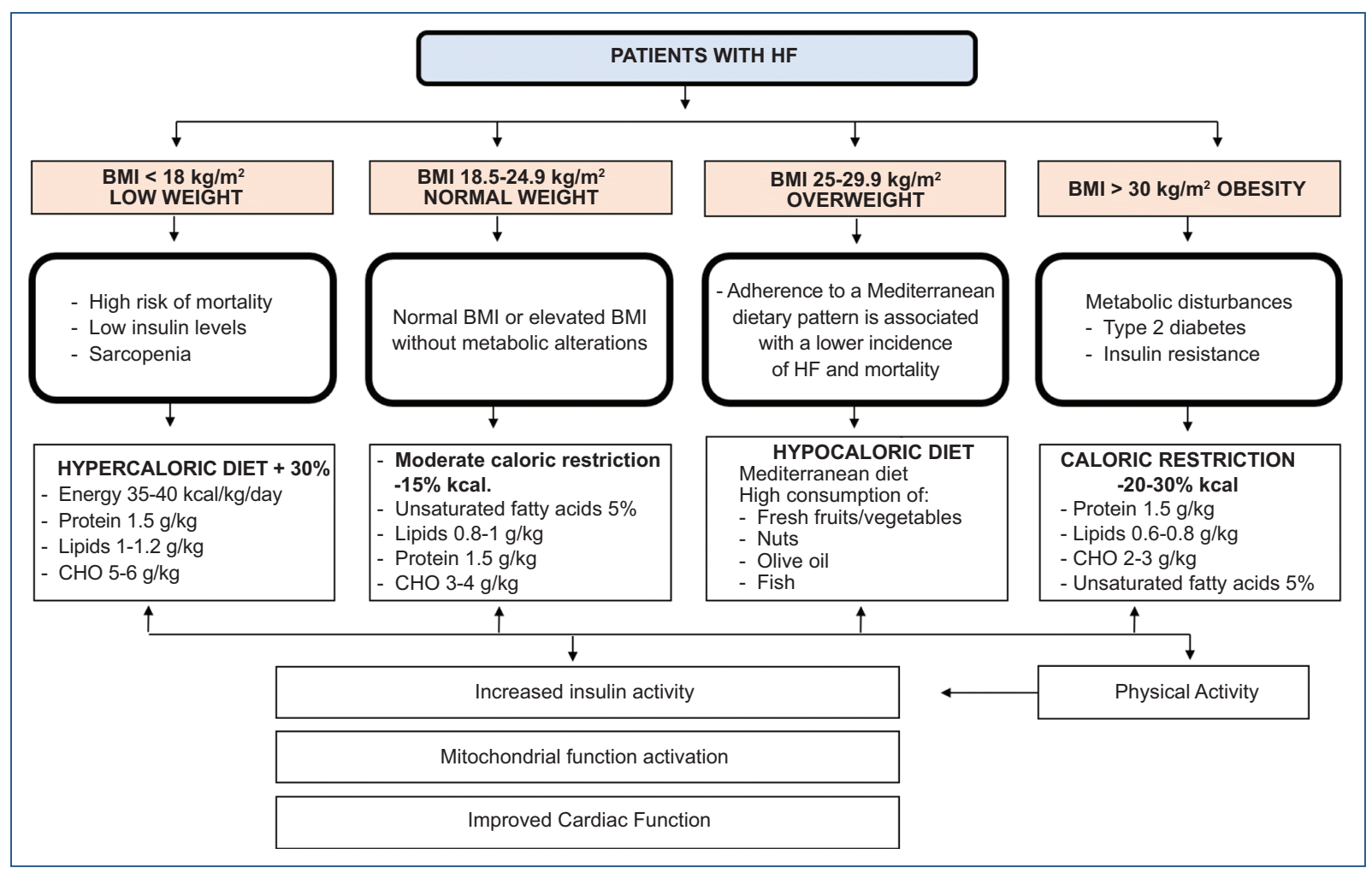

Figure 1. Nutritional indications in patients with heart failure (HF) according to edema-free body mass index (BMI). CHO: carbohydrates.

ventricular function and a reduction in the incidence of $\mathrm{HF}^{38,40}$

There is sufficient evidence supporting sodium restriction in these patients (2-3 g/day), as well as fluid restriction (1-1.5 L/day $)^{41}$. On the other hand, various studies with interventions based on very low sodium diets found that restrictive diets $<2 \mathrm{~g}$ sodium/day may increase the risk of readmission and mortality in patients with $\mathrm{HF}^{41}$.

\section{Nutritional support}

Patients with advanced HF often pose nutritional challenges, owing to the depletion of reserves they experience, which generates weakness and, often, inability to maintain adequate oral intake, which in turn leads to suboptimal nutritional states that are worsened by the need for fasting before certain evaluations or surgical procedures. The need for nutritional support in critically ill patients and in those undergoing surgery is well established; trials on the subject focus on the use of enteral (EN) and parenteral (PN) nutrition. The safety of PN has been demonstrated in patients with ventricular assist devices; however, there is still controversy about early vs. late use. Ingestion or infusion of a carbohydrate solution 2-3 hours prior to major surgery has also been observed to be beneficial. This prevents postoperative insulin resistance associated with endogenous carbohydrate production, decreases postoperative muscle loss and improves immune function ${ }^{42}$.

On the other hand, when the use of the oral route is insufficient or inexistent, EN should be tried even if inotropics are being received, as it has been shown that, even in small amounts, it could be beneficial for stimulating the gastrointestinal mucosa and this way prevent bacterial translocation ${ }^{42}$.

\section{Conclusions}

Malnutrition has been associated with the appearance of various complications in different pathologies (with one of the being HF), especially at advanced stages, such as sarcopenia, dysphagia, CC, as well as a deficiency of multiple micronutrients that, in the long 
term, can evolve into many other pathologies or exacerbate the characteristic symptoms of the disease.

Nutritional treatment is focused on developing an appropriate dietary plan, as well as on the treatment of comorbidities present in patients with HF. Multivitamin supplementation is reserved only for patients with proven micronutrient deficiencies. The use of EN and PN is poorly studied in this entity but, even so, when oral route intake is decreased or practically inexistent and gastrointestinal tract is functional, the use of enteral feeding should be preferred over the parenteral route.

There is a potential benefit of oral nutritional supplements for increasing body weight in patients with HF who are undernourished or at risk of undernourishment, as well as of individualized dietary intervention for reducing mortality and hospital readmission. However, quality of evidence is low, and recommendations for clinical practice cannot currently be made. Better methodological quality studies and with a larger number of participants are needed in order for efficacy of nutritional interventions to be determined in patients with $\mathrm{HF}$ and malnutrition.

\section{Acknowledgements}

The authors thank the Department of Clinical Nutrition at Instituto Nacional de Ciencias Médicas y Nutrición "Salvador Zubirán".

\section{Funding}

This research has not received any specific grant from public, commercial or non-profit sector agencies.

\section{Conflicts of interest}

The authors declare that they have no conflicts of interest.

\section{Ethical disclosures}

Protection of human and animal subjects. The authors declare that no experiments have been performed on humans or animals for this research.

Confidentiality of data. The authors declare that no patient data appear in this article.

Right to privacy and informed consent. The authors declare that no patient data appear in this article.

\section{References}

1. Normand C, Kaye DM, Povsic TJ, Dickstein K. Beyond pharmacological treatment: an insight into therapies that target specific aspects of heart failure pathophysiology. Lancet. 2019;393:1045-55.

2. Benjamin EJ, Blaha MJ, Chiuve SE, Cushman M, Das SR, Deo R, et al. American Heart Association Statistics Committee and Stroke Statistics Subcommittee. Heart disease and stroke statistics-2017 update: a report from the American Heart Association. Circulation. 2017;135:e146-603.

3. Heidenreich PA, Albert NM, Allen LA, Bluemke DA, Butler J, Fonarow GC, et al. Forecastingthe impact of heart failure in the United States: a policy statement from the American Heart Association. Circ Heart Fail. 2013;6(3):606-19.

4. Stevens B, Pezzullo L, Verdian L, Tomlinson J, Estrada-Aguilar C, George A, et al. The economic burden of hypertension, heart failure, myocardial infarction, and atrial fibrillation in Mexico. Arch Cardiol Mex. 2018;88(3):241-4.

5. Carro A, Panisello JM, Coats AJS. Nutritional status in advanced heart failure and heart transplant patients. Rev Esp Cardiol. 2017;70(8):626-8.

6. Rahman A, Jafry S, Jeejeebhoy K, Nagpal AD, Pisani B, Agarwala R Malnutrition and cachexia in heart failure. J Parenter Enteral Nutr. 2016;40(4):475-86.

7. Sze S, Pellicori P, Zhang J, Weston J, Clark AL. Agreement and classification performance of malnutrition tools in patients with chronic heart failure. Curr Dev Nutr. 2020;4(6):nzaa07.

8. Murphy L, Gray A, Joyce E. Anabolism to catabolism: Serologic clues to nutritional status in heart failure. Curr Heart Fail Rep. 2019;16(5):189-200.

9. Raposo André T, Lopes-Santos A. Cardiac cachexia syndrome. Eur Med J Cardiol. 2017;5(1):101-7.

10. Goyal P, Almarzooq ZI, Horn EM, Karas MG, Sobol I, Swaminathan RV et al. Characteristics of hospitalizations for heart failure with preserved ejection fraction. Am J Med. 2016;129(6):635.e15-26.

11. Walker SR, Gill K, Macdonald K, Komenda P, Rigatto C, Sood MM, et al. Association of frailty and physical function in patients with non-dialysis CKD: A systematic review. BMC Nephrol. 2013;14:228-37.

12. McNallan SM, Chamberlain AM, Gerber Y, Singh M, Kane RL, Weston SA, et al. Measuring frailty in heart failure: a community perspective. Am Heart J. 2013;166(4):768-74.

13. Vidan MT, Sanchez E, Fernandez-Aviles F, Serra-Rexach JA, Ortiz J, Bueno H. FRAIL-HF, a study to evaluate the clinical complexity of heart failure in nondependent older patients: rationale, methods and baseline characteristics. Clin Cardiol. 2014;37(12):725-32.

14. Cruz-Jentoft AJ, Bahat G, Bauer J, Boirie Y, Bruyère O, Cederholm T, et al. Sarcopenia: Revised European consensus on definition and diagnosis. Age Ageing. 2019;48:16-31.

15. Von Haehling S. The wasting continuum in heart failure: From sarcopenia to cachexia. Proc Nutr Soc. 2015;74:367-77.

16. Springer J, Springer JI, Anker SD. Muscle wasting and sarcopenia in heart failure and beyond: update 2017. ESC Hear Fail. 2017;4(4):492-8.

17. Zamboni M, Rossi A, Corzato F, Bambace C, Mazzali G, Fantin F. Sarcopenia, cachexia and congestive heart failure in the elderly. Endocrine, Metab Immune Disord Targets. 2013;13(1):58-67.

18. Evans WJ, Morley JE, Argilés J, Bales C, Baracos V, Guttridge D, et al. Cachexia: A new definition. Clin Nutr. 2008;27(6):793-9.

19. Sato Y, Yoshihisa A, Kimishima K, Yokokawa T, Abe S. Prognostic factors in heart failure patients with cardiac cachexia. J Ger Cardiol. 2020;17:26-34.

20. Sciatti E, Lombardi C, Ravera A, Vizzardi E, Bonadei I, Carubelli V, et al. Nutritional deficiency in patients with heart failure. Nutrients. 2016;8(7).

21. Albakri A. Nutritional deficiency cardiomyopathy: A review and pooled analysis of pathophysiology, diagnosis and clinical management. Res Rev Insights. 2019;3(1):1-14.

22. Sharma A, Fonarow GC, Butler J, Ezekowitz JA, Felker GM. Coenzyme Q10 and heart failure. Circ Hear Fail. 2016;9(4):1-9.

23. Sander S, Coleman CI, Patel AA, Kluger J, Michael White C. The impact of coenzyme Q10 on systolic function in patients with chronic heart failure. J Card Fail. 2006;12(6):464-72.

24. Soukoulis V, Dihu JB, Sole M, Anker SD, Cleland J, Fonarow GC, et al. Micronutrient deficiencies. An unmet need in heart failure. J Am Coll Cardiol. 2009;54(18):1660-73.

25. Sica DA. Loop diuretic therapy, thiamine balance, and heart failure. Congest Heart Fail. 2007;13(4):244-7.

26. Schoenenberger AW, Schoenenberger-Berzins R, Auf der Maur C, Suter PM, Vergopoulos A, Erne P. Thiamine supplementation in symptomatic chronic heart failure: study. 2012;101(3):159-64.

27. Siliprandi N, Lisa F Di, Menabò R. Propionyl-L-carnitine: Biochemical significance and possible role in cardiac metabolism. Cardiovasc Drugs Ther. 1991;5(1 Supplement):11-5

28. Krim SR, Campbell P, Lavie CJ, Ventura H. Micronutrients in chronic heart failure. Curr Heart Fail Rep. 2013;10(1):46-53.

29. Amat di San Filippo C, Taylor MRG, Mestroni L, Botto LD, Longo N. Cardiomyopathy and carnitine deficiency. Mol Genet Metab. 2008;94(2):162-6. 
30. Rizos I. Three-year survival of patients with heart failure caused by dilated cardiomyopathy and L-carnitine administration. Am Heart $\mathrm{J}$. 2000;139(2 III):1-4.

31. Zulli A. Taurine in cardiovascular disease. Curr Opin Clin Nutr Metab Care. 2011;14(1):57-60.

32. Amankwah N, Han Z. Cardiomyopathy secondary to selenium deficiency: A review of clinical cases. Open Nutr J. 2018;12(1):74-88.

33. Chen J. An original discovery: Selenium deficiency and Keshan disease (an endemic heart disease). Asia Pac J Clin Nutr. 2012;21(3):320-6.

34. LinH, Zhang H, Lin Z, Li X, Kong X, Sun G. Review of nutritional screening and assessment tools and clinical outcomes in heart failure. Heart Fail Rev. 2016;21:549-65

35. Guigoz Y. The Mini Nutritional Assessment (MNA) review of the literature-what does it tell us? J Nutr Health Aging. 2006;10:466-85

36. Kaiser MJ, Bauer JM, Ramsch C, Uter W, Guigoz Y, Cederholm T, et al. Validation of the Mini Nutritional Assessment Short-Form (MNA-SF): a practical tool for identification of nutritional status. J Nutr Health Aging. 2009;13:782-8.
37. Brink M, Anwar A, Delafontaine P. Neurohormonal factors in the development of catabolic/anabolic imbalance and cachexia. Int $\mathrm{J}$ Cardiol. 2002;85(1):111-21.

38. Bianchi VE. Nutrition in chronic heart failure patients: a systematic review. Heart Fail Rev. 2020 Nov;25(6):1017-26.

39. Nguyen HT, Bertoni AG, Nettleton JA, Bluemke DA, Levitan EB, Burke GL. Dash eating pattern is associated with favorable left ventricular function in the multi-ethnic study of atherosclerosis. J Am Coll Nutr. 2012;31(6):401-7.

40. Tektonidis TG, Åkesson A, Gigante B, Wolk A, Larsson SC. Adherence to a Mediterranean diet is associated with reduced risk of heart failure in men. Eur J Heart Fail. 2016;18(3):253-9.

41. Abshire M, Xu J, Baptiste D, Almansa JR, Xu J, Cummings A, et al. Nutritional interventions in heart failure: A systematic review of the literature. J Card Fail. 2015;21(12):989-99.

42. Marelli D. Nutritional support and advanced heart failure. ASAIO J. 2014;60(4):372-3. 